\title{
Moderate \& Vigorous-Intensity Physical Exercises and Effect on Serum Lipids \& Lipoproteins of Healthy Individuals in Anambra State Nigeria
}

\author{
Saheed Opeyemi Usman ${ }^{1}$, Jude Anaelechi Onuegbu ${ }^{1}$, and Samuel Chukwuemeka Meludu²
}

\begin{abstract}
Background: Variation in lipids and lipoproteins has been implicated in physical exercises, of varying intensity and frequency. This has been largely attributed to decline in physical exercise thus predisposing many to various chronic ailments. Objectives: To determine and compare results of the effect of moderate and vigorous exercises on triglyceride (TG), total cholesterol (TC), high density lipoprotein cholesterol (HDLC) and low density lipoprotein cholesterol (LDLC) before exercise, two weeks after exercise and four weeks after exercise. Methodology: Serum concentration of TG, TC, HDLC \& LDLC of both vigorous exercise group (50 male individuals who played football for 2 hours daily for 5 days/week) and moderate exercise group (50 male individuals who played football for 30 minutes daily for 3 days/week) were determined using enzymatic spectrophotometric method. All data were expressed as Mean \pm Standard Deviation (SD) and analyzed with Analysis of Variance (ANOVA) while multiple comparisons were done using Post Hoc test. Pearson's correlation coefficient was used for correlational analysis. Results: In the moderate exercise group, mean BMI was reduced while HDLC was increased, but no significance at $\mathrm{P}<0.05$ all through. Mean serum TG, TC and LDLC were reduced significantly at $\mathrm{P}<0.05$ mostly 4 weeks after exercise as compared with the results before exercise. In the vigorous exercise group, mean serum TG, TC and LDLC were significantly reduced at $\mathrm{P}<0.05$ almost entirely after exercise as compared with results before exercise and 2 weeks after exercise. Mean serum HDLC was significantly increased all through at $\mathrm{P}<0.05$. However, mean BMI was decreased but not significant at $\mathrm{P}<0.05$. Conclusion: Vigorous physical exercise can substantially increase fitness, but, moderate physical exercise, when performed frequently and over an extended period, produces enhanced biochemical parameters and reduced risks of cardiovascular disease.
\end{abstract}

Keywords - physical exercise, spectrophotometric method, cholesterol, triglyceride.

\section{INTRODUCTION}

$\mathrm{P}$ HYSICAL exercise is any bodily activity that enhances or maintains physical fitness and overall health and wellness. It improves mental health and helps prevent depression [1]. Controversy exists on the specific form of exercise, as

\footnotetext{
${ }^{1}$ Department of Chemical Pathology, Nnamdi Azikiwe University, Awka, Nigeria

${ }^{1}$ Department of Chemical Pathology, Nnamdi Azikiwe University, Awka, Nigeria.

${ }^{2}$ Department of Human Biochemistry, Nnamdi Azikiwe University, Awka, Nigeria
}

well as the intensity, duration, and training intervals of the specific form of exercise chosen as a lifestyle intervention regimen. Moderate and vigorous exercises generally relate to aerobic forms of exercise [2]. The most effective way to participate in a well-rounded physical exercise program is by following a simple short acronym called FITT (Frequency, Intensity, Time, Type). The FITT principle includes how many times a week one should exercise (frequency), how intense the workout should be (intensity), how long the workout is (time), and what modality to use (type of exercise) [3].

Lipids are a large and diverse group of naturally occurring organic compounds that are related by their solubility in nonpolar organic solvents (e.g. ether, chloroform \& benzene) and general insolubility in water. The main biological functions of lipids include energy storage, as structural components of cell membranes, and as important signaling molecules [4]. A lipoprotein is a biochemical assembly that contains both proteins and lipids, which allow fats to move through the water outside cells and inside cells. There are five main classes of lipoproteins: Chylomicrons, Very Low Density Lipoproteins (VLDLC), Intermediate Density Lipoproteins (IDL), Low Density Lipoproteins (LDLC), High Density Lipoproteins (HDLC) [5]. In a study on plasma lipid, lipoprotein profiles in Nigerian university athletes and nonathletes, South-Western Nigeria, reported mean levels of total cholesterol and LDLC cholesterol to be significantly lower in the athletes than in the controls. However, there were no statistically significant differences between the mean values of the plasma triglycerides and HDLC for the athletes and controls [6]. Another study in 2009, on the effect of sedentary work and exercise on lipid and lipoprotein metabolism in middle-aged male and female African workers in Eastern Nigeria reported a statistically significant increase in Total Cholesterol, Triglycerides, LDLC and VLDLC when compared with the control subjects, while the HDLC showed a significant decrease when compared with the control. A statistically significant increase was observed in the lipid profile of sedentary workers not undergoing exercise [7]. The aim of this study is therefore to examine the beneficial effects of moderate and vigorous physical exercises on lipids and lipoproteins of healthy male individuals in Anambra State, Nigeria, as well as, to know the preferred form of physical exercise. 


\section{II.MATERIALS AND METHODS}

\subsection{Study Site/Subject Selection/Study Design}

The study was conducted at Amawbia training ground, Amudo football training ground and Okpuno football training ground, all in Awka metropolis, Anambra State, Nigeria. Total study size of 100 subjects but 300 samples/specimens was used (males). They were divided into two groups: Group 1 (Vigorous Exercise) - This group consisted of 50 individuals (males) who trained for football playing for 2 hours daily (5 days/week). Group 2 (Moderate Exercise) This group consisted of 50 individuals (males) who trained for football playing for 30minutes (3 days/ week). A baseline specimen was obtained from each subject before exercise. After two weeks and four weeks of respective training, fresh samples were collected from each subject.

\subsection{Inclusion and Exclusion Criteria}

Inclusion criteria for subjects were: physically healthy male individual's ages 18 - 35 years, occasional or nonalcohol consumers, non-smokers, as well as, those not on drugs especially that will interfere with the parameters to be studied (e.g. lipid-lowering drugs).

Subjects physically unhealthy (males/females), outside the age range, regular alcohol consumers, smokers and those on drugs especially those that will interfere with the parameters to be studied, were all excluded.

\subsection{Sample Size}

Sample size calculation was done using 95\% confidence interval, 0.05 precision and prevalence rate. There seem to be no data available as regards the proportion of Anambra State residents that participate in various forms of physical exercise, but, high physical activity levels assessed in Ibadan, Western Nigeria, reported $3.2 \%$ [8]. The formula for sample size when population is more than 1000 is: $\mathbf{n}=\mathbf{Z}^{2} \mathbf{P Q} / \mathbf{d}^{2}[9]$.

Where:

$\mathrm{n}=$ sample size,

$\mathrm{d}=$ degree of precision (taken as 0.05 ),

$\mathrm{Z}=$ standard normal deviation at $95 \%$ confidence interval which is 1.96 ,

$\mathrm{P}=$ proportion of the target population (estimated at $3.2 \%$ which is $3.2 / 100=0.032$ ),

$\mathrm{Q}=$ alternate proportion $(1-\mathrm{P})$ which is $1-0.032=0.968$

$$
\mathrm{n}=\frac{(1.96)^{2}(0.032)(0.968)}{(0.05)^{2}}=\mathbf{4 8}
$$

\subsection{Sample Collection, Storage and Analysis}

A $5 \mathrm{ml}$ fasting blood sample was aseptically collected into plain sample containers from each of the participating individuals by venepuncture on each of the three occasions sample was withdrawn between 7.30am and 10am. Blood samples were centrifuged at 4000 Revolution per Minute (RPM) for 10 minutes and the serum of each sample was extracted into fresh plain bottle for analysis. Serum samples were analyzed promptly after centrifugation while those not analyzed immediately analyzed were stored at -20 degree celsius until analysis few days later. Total cholesterol, triglyceride and HDL-Cholesterol were estimated using the enzymatic endpoint spectrophotometric method. LDLCholesterol was estimated by Friedwald's equation calculation.

\subsection{Principle of Spectrophotometry (Beer's \& Lambert's} Law)

When a monochromatic light passes through a coloured solution, its absorbance is proportional to the concentration of the coloured solution and the length of the light path. The intensity of the colour change is proportional to the concentration of the substance being tested.

\subsection{Statistical Analysis}

Data was statistically analyzed using Statistical Package for the Social Sciences (SPSS) for windows version 20.0 software. All data were expressed as Mean \pm Standard Deviation (SD). Statistical analysis of the data before exercise, two weeks after exercise and four weeks after exercise was performed by Analysis of Variance (ANOVA) while multiple comparisons were done using Post Hoc test. Significance was fixed at P < 0.05 and highly significant if $\mathrm{P}<0.01$. Pearson's correlation coefficient was used for correlational analysis of the test.

\section{RESULTS AND ANALYSIS}

\subsection{Physical and Biochemical Parameters}

The mean age for subjects in moderate exercise group was 21.74 years while mean age for subjects in vigorous exercise group was 21.44 years, with the mean age of both groups not significantly different. The mean body mass index (BMI) of both moderate and vigorous exercise groups was reduced but not significantly different before exercise, 2 weeks after exercise or 4 weeks after exercise (Tables $1 \& 2$ ).

In the moderate exercise group, the mean serum concentration of TG, TC and LDLC were significantly reduced at $\mathrm{P}<0.05$ and they were significantly decreased mostly 4 weeks after exercise as compared with the results before exercise. The mean serum concentration of HDLC was increased but not significant at $\mathrm{P}<0.05$. In the vigorous exercise group, the mean serum concentration of TG, TC and LDLC were significantly reduced at $\mathrm{P}<0.05$ almost entirely after exercise as compared with the results before exercise as well as 2 weeks after exercise. The mean serum concentration of HDLC was significantly increased at $\mathrm{P}<0.05$ all through (Tables $1 \& 2$ ).

Pearson product moment correlation analysis was carried out to determine the relationship between parameters or variables. The correlation between parameters before exercise, 2 weeks after exercise, as well as, 4 weeks after exercise in both exercise groups show that there were positive correlations between BMI and TG, TG and TC, as well as, TC and LDLC. Conversely, there was an inverse correlation between HDLC and LDLC). 
TABLE I

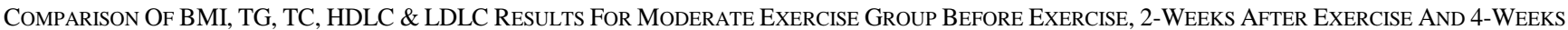
AFTER EXERCISE

\begin{tabular}{|c|c|c|c|c|c|}
\hline \multirow[t]{2}{*}{ Groups } & \multicolumn{3}{|c|}{ Parameters } & & \\
\hline & $\mathrm{BMI}\left(\mathrm{kg} / \mathrm{m}^{2}\right)$ & $\mathrm{TG}(\mathrm{mmol} / \mathrm{L})$ & $\mathrm{TC}(\mathrm{mmol} / \mathrm{L})$ & $\operatorname{HDLC}(\mathrm{mmol} / \mathrm{L})$ & $\mathrm{LDLC}(\mathrm{mmol} / \mathrm{L})$ \\
\hline $\begin{array}{l}\text { Before Exercise } \\
2 \text { weeks after exercise } \\
4 \text { weeks after exercise } \\
\text { F-value } \\
\text { P-value }\end{array}$ & $\begin{array}{l}22.88=0.84 \\
22.87 \pm 0.85 \\
22.69 \pm 0.86 \\
0.821 \\
0.442\end{array}$ & $\begin{array}{l}1.14 \pm 0.24 \\
1.06 \pm 0.24 \\
1.01 \pm 0.27 \\
3.507 \\
0.033^{*}\end{array}$ & $\begin{array}{l}4.04 \pm 0.39 \\
3.89 \pm 0.38 \\
3.83 \pm 0.35 \\
4.062 \\
0.019 *\end{array}$ & $\begin{array}{l}1.21 \pm 0.24 \\
1.27 \pm 0.22 \\
1.32 \pm 0.26 \\
2.352 \\
0.099\end{array}$ & $\begin{array}{l}2.31 \pm 0.46 \\
2.14 \pm 0.44 \\
2.06 \pm 0.46 \\
3.820 \\
0.024^{*}\end{array}$ \\
\hline $\begin{array}{l}\text { POSTHOC } \\
a / b \\
a / c \\
b / c\end{array}$ & $\begin{array}{l}1.000 \\
0.752 \\
0.873\end{array}$ & $\begin{array}{l}0.396 \\
0.028^{*} \\
0.788\end{array}$ & $\begin{array}{l}0.146 \\
0.019^{*} \\
1.000\end{array}$ & $\begin{array}{l}0.770 \\
0.095 \\
0.915\end{array}$ & $\begin{array}{l}0.213 \\
0.022^{*} \\
1.000\end{array}$ \\
\hline
\end{tabular}

KEY:

$\mathrm{a}-$ before exercise $\quad \mathrm{b}-2$ weeks after exercise $\quad \mathrm{c}-4$ weeks after exercise

$*=$ Results compared are significantly different at $\mathrm{P}$-value $<0.05(\mathrm{P}<0.05)$

BMI - Body Mass Index $\left(\mathrm{kg} / \mathrm{m}^{2}\right)$

$\mathrm{TG}$ - Triglycerides $(\mathrm{mmol} / \mathrm{L})$

TC - Total Cholesterol ( $\mathrm{mmol} / \mathrm{L})$

HDLC - High Density Lipoprotein Cholesterol (HDLC) ( $\mathrm{mmol} / \mathrm{L})$

LDLC - Low Density Lipoprotein Cholesterol (LDLC) (mmol/L)

TABLE II

Comparison Of BMI, TG, TC, HDLC \& LDLC Results For Vigorous Exercise Group Before Exercise, 2-Weeks After Exercise AND 4-WEEKS AFTER EXERCISE

\begin{tabular}{|c|c|c|c|c|c|}
\hline \multirow[t]{2}{*}{ Groups } & \multicolumn{5}{|c|}{ Parameters } \\
\hline & $\mathrm{BMI}\left(\mathrm{kg} / \mathrm{m}^{2}\right)$ & $\mathrm{TG}(\mathrm{mmol} / \mathrm{L})$ & $\mathrm{TC}(\mathrm{mmol} / \mathrm{L})$ & $\operatorname{HDLC}(\mathrm{mmol} / \mathrm{L})$ & $\mathrm{LDLC}(\mathrm{mmol} / \mathrm{L})$ \\
\hline Before Exercise & $22.71 \pm 1.20$ & $1.24 \pm 0.27$ & $4.22 \pm 0.31$ & $1.13 \pm 0.23$ & $2.53 \pm 0.24$ \\
\hline 2 weeks after exercise & $22.54 \pm 1.23$ & $1.15 \pm 0.26$ & $4.05 \pm 0.26$ & $1.27 \pm 0.21$ & $2.26 \pm 0.23$ \\
\hline 4 weeks after exercise & $22.22=1.29$ & $0.99 \pm 0.21$ & $3.78=0.25$ & $1.38=0.17$ & $1.95=0.26$ \\
\hline F-value & 2.008 & 12.887 & 32.806 & 19.265 & 71.343 \\
\hline P-value & 0.138 & $0.001^{*}$ & $0.001^{*}$ & $0.001^{*}$ & $0.001^{*}$ \\
\hline \multicolumn{6}{|l|}{ POSTHOC } \\
\hline $\mathrm{a} b \mathrm{~b}$ & 1.000 & $0.009 *$ & $0.002^{*}$ & $0.002^{*}$ & $0.001^{*}$ \\
\hline $\mathrm{a} / \mathrm{c}$ & 0.150 & $0.001^{*}$ & $0.001^{*}$ & $0.001^{*}$ & $0.001^{*}$ \\
\hline$b / c$ & 0.606 & $0.001^{*}$ & $0.001^{*}$ & $0.020^{*}$ & $0.001^{*}$ \\
\hline
\end{tabular}

KEY:

a - before exercise $\quad b-2$ weeks after exercise $\quad c-4$ weeks after exercise

$*=$ Results compared are significantly different at $\mathrm{P}$-value $<0.05(\mathrm{P}<0.05)$

BMI - Body Mass Index $\left(\mathrm{kg} / \mathrm{m}^{2}\right)$

TG - Triglycerides $(\mathrm{mmol} / \mathrm{L})$

TC - Total Cholesterol (mmol/L)

HDLC - High Density Lipoprotein Cholesterol (HDLC) (mmol/L)

LDLC - Low Density Lipoprotein Cholesterol (LDLC) ( $\mathrm{mmol} / \mathrm{L})$

\section{DISCUSSION}

The mean age and body mass index (BMI) of both moderate and vigorous exercise groups were not significantly different before exercise, 2 weeks after exercise or 4 weeks after exercise. In the moderate exercise group, the mean serum concentration of TG, TC \& LDLC were significantly reduced at $\mathrm{P}<0.05$ mostly 4 weeks after exercise as compared with results before exercise. The mean serum concentration of HDLC was increased but not significant at $\mathrm{P}<0.05$. In the vigorous exercise group, the mean serum concentration of TG, TC and LDLC were significantly reduced at $\mathrm{P}<0.05$ almost entirely after exercise as compared with the results before exercise as well as 2 weeks after exercise. The mean serum concentration of HDLC was significantly increased at $\mathrm{P}<0.05$ all through. These findings are in agreement with some of the findings of a 2009 study which reported increases in level of 
physical activity were associated with increases in HDLC and decreases in TG among the participants [10]. These results show a reverse of a 2009 study which reported increases in the concentrations of TC, TC, LDLC \& VLDLC in sedentary workers as compared with controls [7]. The study is in deviation from the result of a another study which reported significantly lower concentrations of TC \& LDLC, but, no significant differences in TG \& HDLC in Nigerian university athletes as compared to non-athletes [6].

The findings of increased HDLC and decreased TG, TC and LDLC in both moderate and vigorous exercise groups might be attributed to increased lipoprotein lipase (LPL) activity in the adipose tissue and muscle, and reduced hepatic lipase (HPL) activity. Lipoprotein lipase (LPL) is the key enzyme for the breakdown of triglyceride-rich lipoproteins (including chylomicrons and Very Low Density Lipoprotein) while Hepatic Lipase (HPL) is a lipolytic enzyme that has role in HDLC metabolism, by hydrolyzing triglyceride and phospholipid in HDLC and also stimulates HDLC cholesterol ester uptake by hepatocytes. The elevation in LPL activity suggests that enhanced lipolysis of triglyceride-rich lipoproteins may be an initial step in higher serum levels of HDLC. Furthermore, HPL catalyzes the conversion of the larger HDLC particles containing phospholipids, to the smaller HDLC particles that are rapidly catabolized, thus, a reduced HPL activity in physical exercise, may lead to slower catabolism of the larger HDLC which may be more cardio protective. The decreases in the serum concentrations of TG, TC and LDLC might therefore, indicate that cholesterol was transported from peripheral tissues to the liver for degradation during the physical exercises. The implication of decreased LDLC and increased HDLC stress the protective effect of physical exercises against cardiovascular diseases and other associated disorders. The HDLC helps in transporting cholesterol from peripheral tissues to the liver for degradation. The decrease in LDLC and increase in HDLC in both moderate and vigorous exercise groups confirms the inverse correlation that was observed between HDLC and LDLC throughout the study in both groups.

\section{V.CONCLUSION}

Vigorous physical exercise can substantially increase fitness, but, moderate physical exercise, when performed frequently and over an extended period, produces enhanced biochemical parameters and reduced risks of cardiovascular disease.

\section{REFERENCES}

[1] D. Malatesta, C. Werlen, S. Bulfaro, X. Chenevière, F. Borrani. Effect of high-intensity interval exercise on lipid oxidation during postexercise recovery. Med. Sci. Sports Exerc, 2009, 41 (2): 364 - 374. http://dx.doi.org/10.1249/MSS.0b013e3181857edo

[2] Centers for Disease Control and Prevention (CDC). General Physical Activities Defined by Level of Intensity. 2011.

[3] American College of Sports Medicine (ACSM). ACSM's Guidelines for Exercise Testing and Prescription. 2000. 6th ed.

[4] E. Fahy, S. Subramaniam, R. Murphy, M. Nishijima, C. Raetz, T. Shimizu, F. Spener, G. Van Meer, M. Wakelam, E.A. Dennis. Update of the comprehensive classification system for lipids. Journal of Lipid Res, 2009, 50: S9 - S14.
http://dx.doi.org/10.1194/jlr.R800095-JLR200

[5] Garrett \& Grisham. Biochemistry. 1995. $2^{\text {nd }}$ ed.

[6] O.O. Oyebola and M.A. Rufai. Plasma lipid, lipoprotein and apolipoprotein profiles in Nigerian university athletes and nonathletes. Br. J. Sp. Med, 1993, 27 (4).

[7] E.J. Ikekpeazu, E.C. Neboh, I.A. Maduka, S.C. Ufelle, C.E. Iyida, F.G. Ejezie, E. Anyanwu. Effect of Sedentary Work and Exercise on Lipid and Lipoprotein Metabolism in Middle-aged Male and Female African Workers. Asian J. Med. Sci, 2009, 1 (3): 117-120.

[8] N.A. Odunaiya, O.A. Ayodele, O.O. Oguntibeju. Physical activity levels of senior secondary school students in Ibadan, Western Nigeria. The Wester. Med. J, 2010, 22: 5 - 6 .

[9] W.W. Daniel. Biostatistics: A Foundation for Analysis in the Health Sciences. 2013. $10^{\text {th }}$ ed.

[10] L.M. Keri, M.B. Christie, E.N. Kari. Longitudinal impact of physical activity on lipid profiles in middle-aged adults: the atherosclerosis risk in communities study. J Lipid Res, 2009, 50 (8): 1685 - 1691. http://dx.doi.org/10.1194/jlr.P900029-JLR200 